\title{
Effect of Warm Mix Asphalt Additives on Freeze-Thaw Resistance of Crumb Rubber Modified Bituminous Mix
}

\author{
Er. Shah Fahad Riyaz \\ Research Scholar, Dept. of Civil Engineering \\ Indo-Global Group of Colleges \\ Abhipur, Mohali, India
}

\author{
Er. Usman Khan \\ Research Scholar, \\ Dept. of Civil Engineering \\ NIT Srinagar \\ Jammu and Kashmir, India
}

\author{
Er. Parvinderjeet Kaur \\ Assistant Prof, Dept. of Civil Engineering \\ Indo-Global Group of Colleges \\ Abhipur, Mohali. India
}

\begin{abstract}
IN the present study an attempt is made to assess and evaluate the effects of repeated freezing and thawing on Crumb Rubber Modified Bitumen (CRMB) hot mix as well as CRMB warm mix made from Warm Mix Asphalt (WMA) additives Sasobit and Zycotherm by carrying out experimental investigations such as Marshall mix design test to evaluate stability, flow and void characteristics of samples. Samples from each of the mixes were

the grading of Bituminous Concrete (Grade II) with bitumen content fixed at $5.4 \%$ from Marshall mix design and crumb rubber content fixed at $15 \%$ by weight of the binder based on literature survey. The amount of additives for the CRMB warm mixes was also fixed on the basis of literature survey as $1.5 \%$ by weight of binder for Sasobit and $0.15 \%$ by weight of binder for Zycotherm . Moreover, the focus has been on exploring options to enhance the condition of pavements and save subsequent maintenance and frequent overlaying expenses in cold regions such as Kashmir valley where the asphalt pavements undergo accelerated deterioration due to seasonal freezing-thawing.
\end{abstract}

Keywords: Pavement, Bitumen, Crumb Rubber, Bituminous Concrete, Warm Mix Asphalt, Zycotherm,

\section{INTRODUCTION}

The abundance and increase of waste tyres and their disposal is a serious problem that leads to environmental pollution. The old practice of disposing waste tyres in sanitary landfills or burning them openly is becoming unacceptable in the present scenario because of depletion of available sanitary landfill sites and environmental concerns respectively. Studies have shown that the crumb rubber obtained from shredding of scrap tyres from automobiles enhances the properties of bitumen leading to excellent pavement life, driving comfort and low maintenance of pavement. Bitumen used for road construction in India is estimated to be 5 million tonnes per year. An average of 750,000 tonnes of crumb rubber can be put to use annually if used as modifier in bitumen for pavements. The use of crumb rubber waste in hot bituminous mixes enhances pavement performance, protects the environment and provides low cost and greener roads. Majority road network in India comprises of flexible pavement in which Hot Mix Asphalt (HMA) is used in the bituminous layer. However, Warm Mix Asphalt (WMA) is helpful in certain situations where the problems associated with HMA may need to be reduced. Warm mix asphalt lowers the mixing temperatures at which asphalt pavement materials are mixed and laid at site. The advantages of WMA are reduced emissions, improved workability, longer construction season and reduced energy consumption. Using crumb rubber and WMA in pavements thus has ample environmental benefits in addition to being economical. The use of such materials can be helpful in achieving the goal of sustainable development.

\section{LITERATURE REVIEW}

Presently in India bitumen modified with various types of modifier such as crumb rubber, natural rubber, reclaimed polyethylene and polymers are being used for construction of bituminous roads. A number of products are also available in the market with which bitumen has been modified. Readily blended type of Polymer modified bitumen, crumb rubber modified bitumen and natural rubber modified bitumen are also available in the market in commercial form. As per IRC: SP: 53-2010 these products shall be evaluated for their suitability in an approved laboratory by conducting various tests to know its properties. Limited work has been reported on the various factors such as the effect of temperature, freezing-thawing, addition of WMA additives, mixture stiffness, aggregate type and gradation and method of testing on behaviour of polymer modified bituminous mixes.

\section{OBJECTIVES OF THE STUDY}

1) To study the effects of 2,4,6, and 8 freeze-thaw cycles on the performance of CRMB in HMA and WMA mixes.

2) To compare the performance of WMA additives viz. Sasobit and Zycotherm in CRMB.

3) To evaluate the Marshall stability, Marshall flow, specific gravity and void characteristics of various CRMB samples at varying freeze-thaw cycles. 
4) To recommend a suitable WMA additive compatible with CRMB best suited for a region experiencing sub-zero temperatures based on the study.

5) To suggest future scope of work that can be carried out in the area of study.

\section{METHODOLOGY}

Various materials were procured in order to perform this study such as aggregates, bitumen binder, fillers, crumb rubber, WMA additives etc and the standard tests were performed on each. The coarse aggregate used in this study were collected from a local stone crusher. Fine aggregates were collected from the crusher with fractions retained on $0.075 \mathrm{~mm}$ IS sieve and passing $4.75 \mathrm{~mm}$ IS sieve. OPC has been used as filler and paving grade bitumen (VG-10) has been used as the binder. The bitumen modifier used is crumb rubber corresponding to mesh size 80 and the amount of crumb rubber was taken as $15 \%$ by weight of bitumen (optimum) based on literature survey to make HMA mix. (Tefera et al. 2018). WMA was prepared for this study using Sasobit and Zycotherm as additives. Sasobit added to CRMB mix was taken $1.5 \%$ by weight of bitumen (optimum) based on literature survey to make WMA mix designated henceforth as S-CRMB. (Arshad et al. 2012). Zycotherm added to CRMB mix was taken $0.15 \%$ by weight of bitumen (optimum) based on literature survey to make WMA mix designated henceforth as ZCRMB (Prajapati et al. 2015). Standard tests on aggregate like gradation, crushing test, Los Angeles abrasion test, aggregate impact test, soundness test, shape test, specific gravity and water absorption test as well as stripping value test were conducted as per IS:2386 and IS:6241. Aggregate grading conforming to B.C (grading-II) as per the MoRT\&H specification was used for the present study. Tests conducted on the binder include penetration test, ductility test, softening point test, specific gravity test, flash and fire point test and viscosity test as per standards specified by IS:1202-1978 to IS:1209-1978. Wet mixing method was employed in this study for mixing of crumb rubber with bitumen. In this method thorough mixing of the crumb rubber in hot bitumen is done by holding the resulting blend at around $180^{\circ} \mathrm{C}$ for a designated minimum period of time (typically 30 minutes) to permit an interaction between the crumb rubber and bitumen. The bituminous mix was designed by using Marshall Method of mix design. The Marshall test was used to obtain the optimum bitumen content based on ASTM D-1559-96. In this case the optimum bitumen content turned out to be $5.4 \%$.

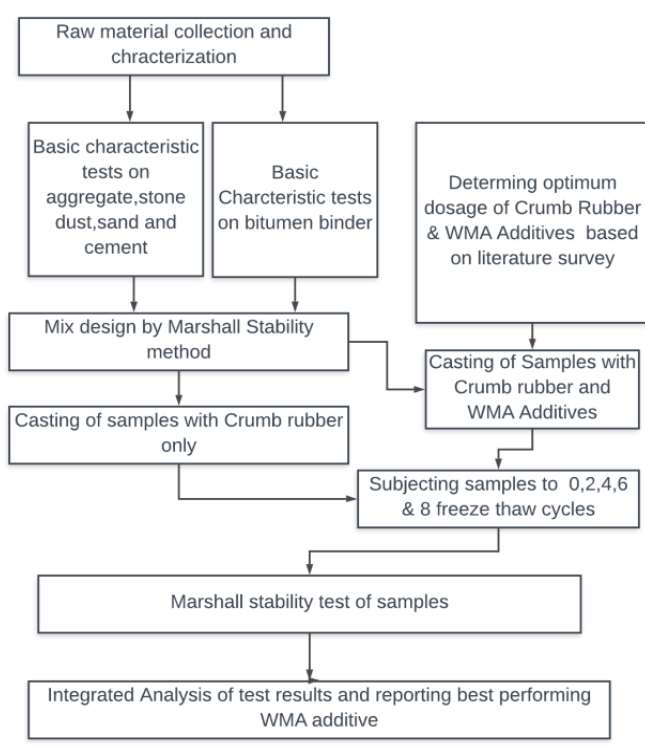

Figure 1. Flow chart showing methodology implemented in the study.

The processes of freeze-thaw were designed and performed as follows:

1. The samples were divided into several groups. Each group consisted of three samples. One group of samples was placed at room temperature and other groups of samples were immersed into a water bath for 0.5 hours.

2. Each sample was taken out of the tank and placed into a plastic bag with $10 \mathrm{ml}$ of water. The bag was put in refrigerator for 16 hours at $-20^{\circ} \mathrm{C}$ until all the water in plastic bag was frozen.

3. The samples were removed from plastic bags and placed into a water bath for 8 hours with constant temperature $60^{\circ} \mathrm{C}$ until thawing process was completed.

4. After steps (1), (2), and (3), one F-T cycle was completed. In this study, the number of F-T cycles performed was 2, 4, 6 and 8 for Marshall Stability and void analysis to be tested at each.

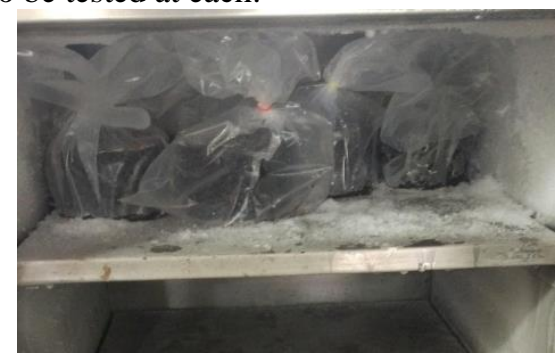

Figure 2. Samples being put in deep freezer for freezing. 


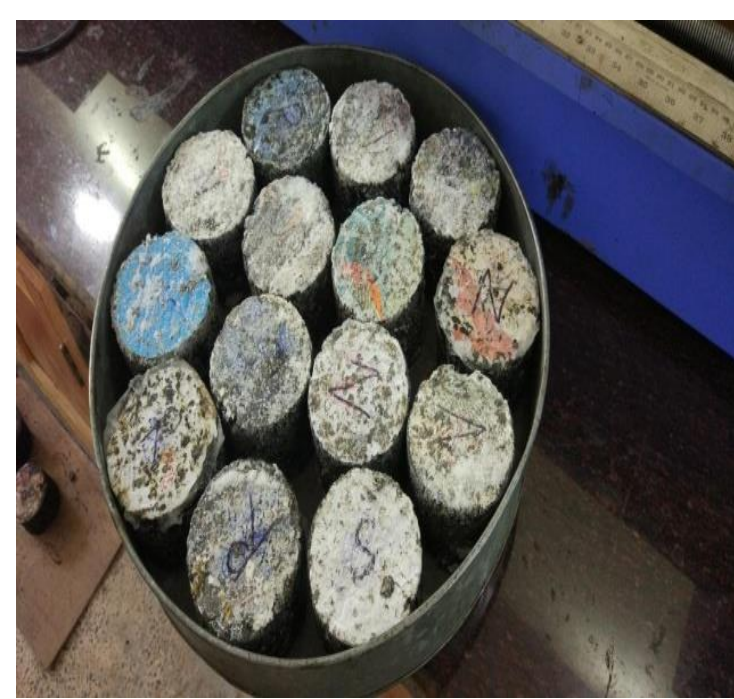

Figure 3. Frozen samples after being taken out from freezer.

\section{RESULTS AND DISCUSSION}

5.1 Variation of Marshall Stability and Flow

Marshall stability and Marshall flow for the samples of the HMA mix i.e. Crumb Rubber Modified Bitumen mix (CRMB), WMA mixes i.e. Sasobit+CRMB (S-CRMB) and Zycotherm+CRMB (Z-CRMB) for normal samples and samples subjected to $2,4,6$, and 8 freeze-thaw cycles are tabulated below.

\subsection{Variation of Air Voids, Unit weight, VMA and VFB.}

Results of the void characteristics for the samples of the HMA mix i.e. Crumb Rubber Modified Bitumen (CRMB), WMA mixes i.e. Sasobit+CRMB (S-CRMB) and Zycotherm+CRMB (Z-CRMB) for normal samples and samples subjected to $2,4,6$, and 8 freeze-thaw cycles are tabulated below

Table 1. Marshall test results for all F-T cycles.

\begin{tabular}{|c|c|c|c|c|c|c|}
\hline \multirow{2}{*}{ Freeze-Thaw Cycles } & \multicolumn{3}{|c|}{ Marshall Stability (KN) } & \multicolumn{3}{c|}{ Marshall Flow (mm) } \\
\cline { 2 - 7 } & CRMB & S-CRMB & Z-CRMB & CRMB & S-CRMB & Z-CRMB \\
\hline 0 & 12.16 & 10.51 & 9.20 & 5.23 & 5.97 & 5.07 \\
\hline 2 & 9.48 & 8.83 & 6.76 & 4.67 & 4.87 & 5.10 \\
\hline 4 & 8.07 & 7.63 & 6.00 & 4.77 & 4.93 & 5.03 \\
\hline 6 & 6.10 & 6.76 & 4.80 & 4.53 & 4.80 & 4.77 \\
\hline 8 & 5.67 & 6.21 & 4.03 & 4.50 & 4.77 & 4.73 \\
\hline
\end{tabular}

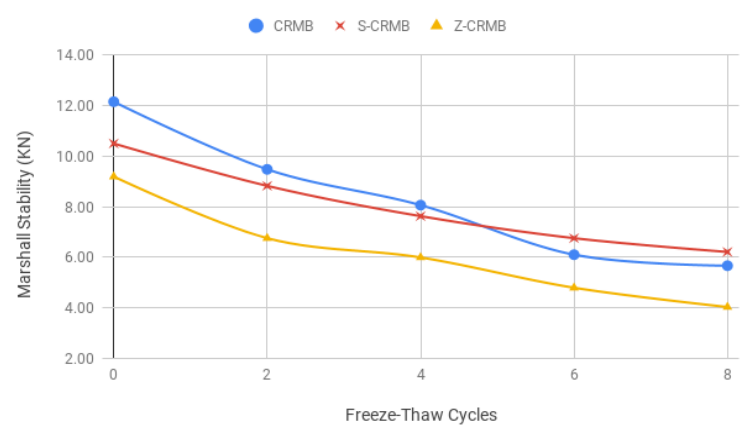

Figure 4. Variation of Marshall Stability with F-T Cycles.

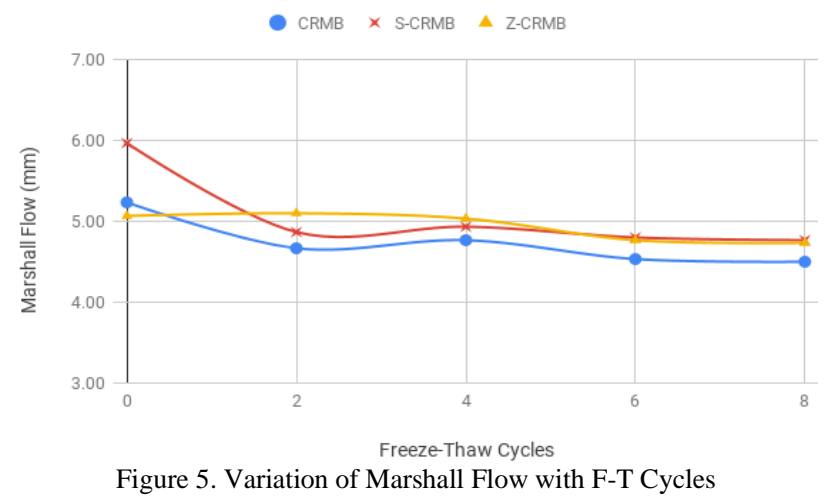


Table 2. Void characteristics for all F-T cycles.

\begin{tabular}{|c|c|c|c|c|c|c|c|}
\hline Freeze-thaw cycles & $\begin{array}{l}\text { Wt. in Air } \\
\text { (gm) }\end{array}$ & $\begin{array}{l}\text { Wt. in Water } \\
\text { (gm) }\end{array}$ & $\begin{array}{c}\mathbf{G}_{\mathbf{m}} \\
(\mathrm{gm} / \mathrm{cc})\end{array}$ & $\begin{array}{l}\text { Va } \\
(\%)\end{array}$ & $\begin{array}{l}\text { Vb } \\
(\%)\end{array}$ & $\begin{array}{c}\text { VMA } \\
(\%)\end{array}$ & $\begin{array}{l}\text { VFB } \\
(\%)\end{array}$ \\
\hline \multicolumn{8}{|c|}{ Crumb Rubber only (CRMB) } \\
\hline 0 & 1351 & 768 & 2.31 & 4.14 & 11.9 & 16.04 & 74.18 \\
\hline 2 & 1230 & 690 & 2.27 & 5.80 & 11.7 & 17.5 & 66.85 \\
\hline 4 & 1289 & 715 & 2.24 & 7.05 & 11.6 & 18.65 & 62.2 \\
\hline 6 & 1238 & 684 & 2.23 & 7.46 & 11.5 & 18.96 & 60.65 \\
\hline 8 & 1314 & 722 & 2.21 & 8.29 & 11.7 & 20 & 58.5 \\
\hline \multicolumn{8}{|c|}{ Crumb Rubber with Sasobit (S-CRMB) } \\
\hline 0 & 1284 & 723 & 2.28 & 5.39 & 11.8 & 17.19 & 68.64 \\
\hline 2 & 1291 & 721 & 2.26 & 6.22 & 11.7 & 17.92 & 65.29 \\
\hline 4 & 1273 & 710 & 2.26 & 6.22 & 11.7 & 17.92 & 65.29 \\
\hline 6 & 1266 & 702 & 2.24 & 7.05 & 11.6 & 18.65 & 62.20 \\
\hline 8 & 1276 & 707 & 2.24 & 7.05 & 11.6 & 18.65 & 62.20 \\
\hline \multicolumn{8}{|c|}{ Crumb Rubber with Zycotherm (Z-CRMB) } \\
\hline 0 & 1261 & 708 & 2.28 & 5.39 & 11.8 & 17.19 & 68.64 \\
\hline 2 & 1245 & 694 & 2.26 & 6.22 & 11.5 & 17.72 & 64.9 \\
\hline 4 & 1311 & 730 & 2.25 & 6.63 & 11.6 & 18.23 & 63.63 \\
\hline 6 & 1284 & 714 & 2.25 & 6.63 & 11.6 & 18.23 & 63.63 \\
\hline 8 & 1334 & 742 & 2.23 & 7.46 & 11.5 & 19.6 & 58.67 \\
\hline
\end{tabular}

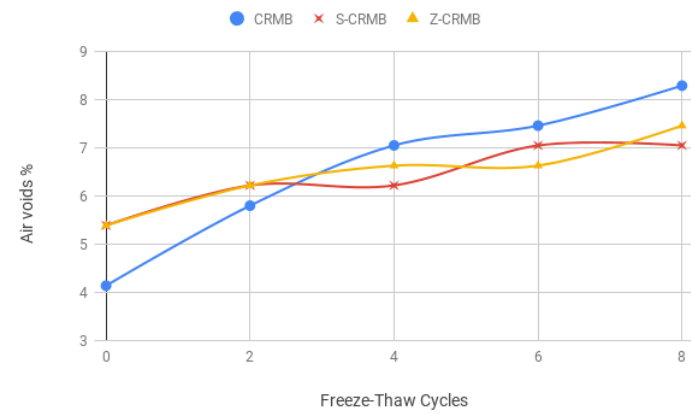

Figure 6. Variation of Air voids with F-T Cycles.

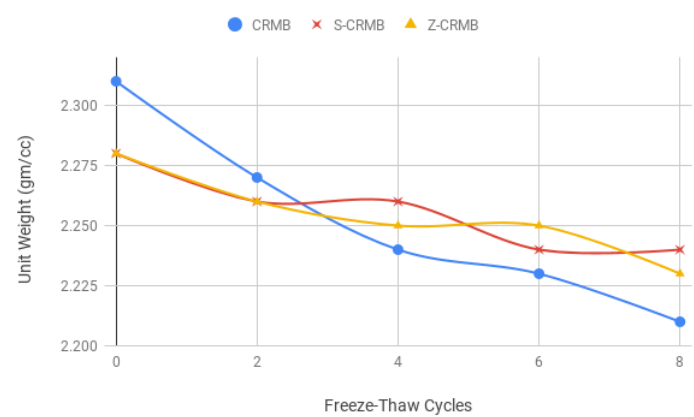

Figure 7. Variation of Unit weight with F-T Cycles.

\section{CONCLUSION AND FUTURE SCOPE}

In this study various tests were conducted on the CRMB HMA mix as well as CRMB WMA mixes to evaluate the effect of repeated freezing and thawing on the properties of the bituminous mixes. Based on these test results, following conclusions were made:

After 8 F-T cycles, stability of S-CRMB was greater than CRMB and Z-CRMB by $10 \%$ and $55 \%$ respectively.

S-CRMB had lesser air voids compared to CRMB and ZCRMB by $15 \%$ and $5.5 \%$ respectively after 8 cycles

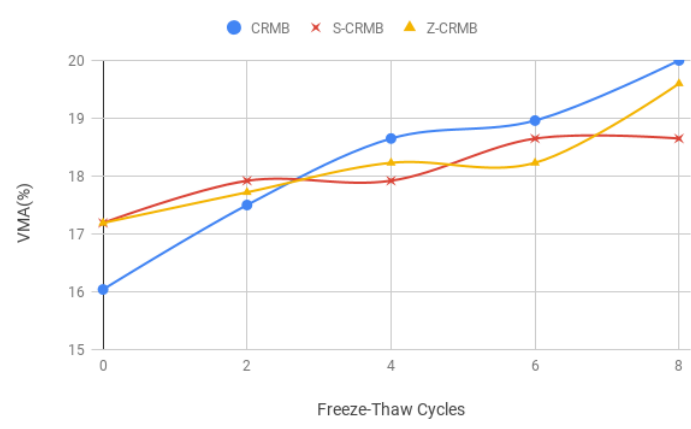

Figure 8. Variation of VMA(\%) with F-T Cycles. 


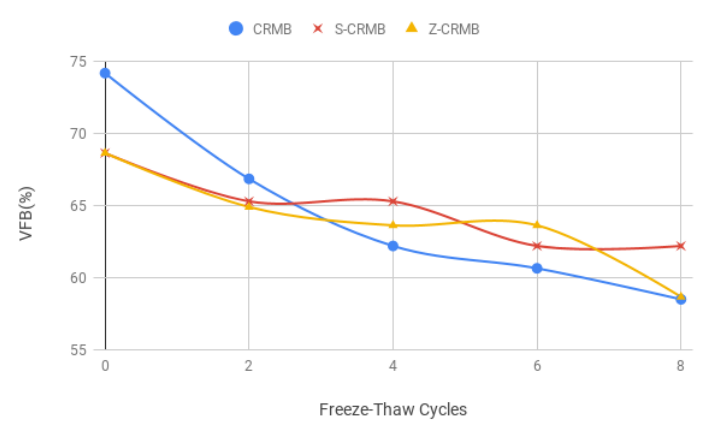

Figure 9. Variation of VFB(\%) with F-T Cycles.

- After 4 freeze-thaw cycles S-CRMB showed the higher density compared to CRMB and Z-CRMB

- The Marshall flow values for all mixes remained 1) in the same range after 2 freeze-thaw cycles.

- Sasobit showed best performance among the two WMA technologies used in this study as shown by the results of Marshall stability and volumetric analysis

In the future course of research, the mixes can be evaluated for indirect tensile stress test, tensile strength ratio etc. Also, the freeze-thaw effects on rutting resistance, skid resistance and fatigue performance of various WMA mixes with CRMB can be studied.

\section{REFERENCES}

[1] Mix design methods for Asphalt concrete and other hot- mix types, Asphalt institute manual series NO.2 (MS-2).

[2] Ministry of Road Transport \& Highways (MORT\&H), "Specifications for road and bridge works".

[3] Bureau of Indian standards, paving bitumen-specification (third revision) IS 73:2006

[4] Bureau of Indian standards IS 1202-1209:1978.

[5] Bureau of Indian standards IS 6241:1971.

[6] Bureau of Indian standards IS 2386:1963 (Part 1-5).

[7] Indian Roads Congress, IRC SP: 53-2002, 2004, 2010 "Guidelines on the use of polymer and crumb rubber."

[8] American Society for Testing and Materials, ASTM D6927. "Standard test method for Marshall stability and flow of asphalt mixtures".

[9] American Association of State Highway and Transportation Officials, AASHTO T-166.

[10] Sharma, Ankit, Mohammad Shafi Mir, and Mohammad Adnan Farooq. "Performance of WMA additives under freeze-thaw action." Road Materials and Pavement Design (2018): 1-13

[11] Tefera et al. "Evaluation of the Effect of Rubber Modified Bitumen on Asphalt Performance." American Journal of Civil Engineering 6.3 (2018): 87-92.
[12] Singh, Harpreet, et al. "Effect of Zycotherm on the Performance of Bituminous Concrete." International Journal of Civil Engineering 8.8 (2017).

[13] Prajapati, R. R., Chotalia, H. P., Vahora, S. I., Patel, A. D., \& Mishra, C. B. (2015). "Gauging the properties of CRMB 60 in mix design with Zycotherm as warm mix additive." International Journal of Current Engineering and Technology, 5(3), 1612-1617.

[14] Ibrahim, Mohd Rasdan, et al. "A review on the effect of crumb rubber addition to the rheology of crumb rubber modified bitumen." Advances in Materials Science and Engineering (2013).

[15] Arshad, A. K., Sukaimy, M. F., Kamaluddin, N. A., \& Daud, N. L. M. (2012). "Evaluation on volumetric properties and resilient modulus performance of warm mix asphalt." International Sustainability and Civil Engineering Journal, 1(1), 25-32.

[16] Mallick, Rajib B., Prithvi S. Kandhal, and Richard L. Bradbury. "Using warm-mix asphalt technology to incorporate high percentage of reclaimed asphalt pavement material in asphalt mixtures." Transportation Research Record 2051.1 (2008): 71-79. 